Portland State University

PDXScholar

Engineering and Technology Management

Faculty Publications and Presentations

$1-1-1997$

\title{
An Introduction To Data Envelopment Analysis In Technology Management
}

Keith Hollingsworth

Morehouse College

Timothy R. Anderson

Portland State University, tim.anderson@pdx.edu

Follow this and additional works at: https://pdxscholar.library.pdx.edu/etm_fac

Part of the Engineering Commons

Let us know how access to this document benefits you.

\section{Citation Details}

Anderson, T.R., "An Introduction To Data Envelopment Analysis In Technology Management," Innovation in Technology Management - The Key to Global Leadership. PICMET '97: Portland International Conference on Management and Technology, pp.773.

This Article is brought to you for free and open access. It has been accepted for inclusion in Engineering and Technology Management Faculty Publications and Presentations by an authorized administrator of PDXScholar. Please contact us if we can make this document more accessible: pdxscholar@pdx.edu. 


\section{An Introduction to Data Envelopment Analysis in Technology Management}

\author{
Timothy R. Anderson \\ Engineering Management Program \\ Portland State University \\ Portland, OR 97207-0751 USA
}

\author{
Keith B. Hollingsworth \\ Department of Economics and Business Administration \\ Morehouse College \\ Atlanta, GA 30314 USA
}

\begin{abstract}
Productivity is a major source of competitive advantage but improving productivity requires analysis and productivity is getting more difficult to measure as economies become more knowledge, service, and innovation intensive. In this paper, we will provide an introduction to a powerful productivity analysis tool, Data Envelopment Analysis (DEA). DEA is a flexible tool originally created in the 1970s for examining the relative efficiency of non-profit institutions. Researchers have found many more applications and created numerous extensions to DEA. This paper provides an introduction to DEA, a summary of some of the most important modeling variations, and examples of applications relevant to technology management.
\end{abstract}

\section{INTRODUCTION}

\section{A. Why Study Productivity Analysis}

Peter Drucker has recently stated [19] that “...productivity is the true source of competitive advantage." While it is a common syndrome that many people become enamored with technology for the sake of technology itself, the real purpose of technology is to directly or indirectly improve productivity.

Productivity is a major source of competitive advantage but improving productivity requires analysis and productivity is getting more difficult to measure as economies become more knowledge, service, and innovation intensive. Traditional productivity measures require aggregating everything into a single measure such as money. This aggregation presupposes known prices for factors of production. While the challenge of determining prices was tractable in the past when labor and capital were the primary constituents of production, it is becoming increasingly difficult. A single set of costs is being made more difficult by the increasingly international orientation of most companies, knowledge intensive products, shifts from product to service orientations, complex organizational structures including outsourcing and virtual organizations, and the shortening of product life cycles.

In this paper, we will provide an introduction to a powerful productivity analysis tool, Data Envelopment Analysis (DEA). DEA is a flexible tool originally created in the 1970s for examining the relative efficiency of non-profit institutions. Since that time, researchers have found many more applications and created numerous extensions to DEA. A major advantage of DEA is that it is not based on knowing the production function thus allowing for richer models and does not rely upon knowledge of the prices of production factors. This paper provides an introduction to DEA, a summary of some of the most important modeling variations, and examples of applications relevant to technology management.

We will focus upon the so-called radial models. While there are additional models such as the additive model and multiplicative models, the radial models have been the focus of the vast majority of the applications as well as the important modeling extensions.

\section{DEVELOPMENT OF THE BASIC DEA MODELS}

\section{A. Background}

Although the origin of DEA is generally accepted as beginning with the seminal work of [16], like most important scientific discoveries, it builds on a strong foundation of developments in the area of production theory such as the works of Farrell [18, 20], Koopmans [29], and others.

As with most optimization based systems, there are two fundamentally different approaches that yield essentially equivalent solutions. These approaches correspond to the primal and dual formulations. We will trace our way through an intuitive explanation of both formulations. An intuitive understanding of the interpretations for both formulations is important since they each have subtle implications for how well a DEA analysis actually fits a particular application. The selection of which model is the primal and which is the dual is of course, arbitrary, so we will follow the conventions set forth in [15] which has attempted to standardize the notation of DEA.

\section{B. Numerical Example}

A numerical example will be used to help illustrate the various DEA models. Consider the case of evaluating a set of software development teams. Each team is made up of a number of junior and senior programmers which will be termed the inputs. The accomplishments (or outputs) of the teams are listed by total number of lines of code and by the number of projects undertaken. Further refinements to these measures could be easily made by including the years of experience of the programmers or categorizing the difficulty of projects. This additional complexity would not prevent the use of DEA but would make an intuitive explanation more difficult so this simple model will suffice for the sake of illustration. We should therefore assume for now that all of the junior programmers are essentially equally skilled; all of the senior programmers are essentially equally skilled; and a line of code has a consistent complexity. This data is summarized in the 
following table. The selection of inputs and outputs should never be viewed as a trivial task. On the contrary, it is a subtle issue which requires a thorough knowledge of the application area. As a basic rule, inputs are "bads" and outputs are "goods." For further discussion, see [33, 43].

TABLE I

SOFTWARE PROGRAMMING TEAMS

\begin{tabular}{|c|c|c|c|c|}
\hline Team & $\begin{array}{c}\text { Junior } \\
\text { Programmers }\end{array}$ & $\begin{array}{c}\text { Senior } \\
\text { Programmers }\end{array}$ & $\begin{array}{c}\text { Lines of } \\
\text { Code }\end{array}$ & Projects \\
\hline $\mathbf{1}$ & 6 & 3 & 12500 & 4 \\
\hline $\mathbf{2}$ & 5 & 2 & 13000 & 5 \\
\hline $\mathbf{3}$ & 7 & 4 & 14500 & 8 \\
\hline $\mathbf{4}$ & 3.5 & 2 & 8000 & 4 \\
\hline $\mathbf{5}$ & 6 & 3 & 13250 & 6 \\
\hline
\end{tabular}

Since we assume each team has the freedom to decide how to best allocate their inputs to produce outputs, we will refer to them as decision making units (DMUs.) Our goal is to measure the productivity of each software development team. This would enable us to determine things such as what are the "best practices" in the area of software development, which teams should be rewarded, what are the performance targets they are given, etc.

\section{CCR Primal Formulation}

Perhaps the first approach to come to mind would be to see if any team used more inputs (programmers) to produce less outputs (both lines of code and number of projects) than one of the other teams. In our example, this would be the case of Team 1 being outperformed (or dominated) by Team 2 . Note that all of the other teams are undominated. This technique does not provide a lot of discriminating power. While this is an important case, it is relatively rare that DMUs are purely dominated by a single other DMU. Still, this technique has found useful application as demonstrated by [47].

Rather than limit ourselves to only those teams that actually exist, if we assume that "composite" or "virtual" teams could be formed from multiples of the other teams, it considerably broadens our possible comparison set. Each team (or DMU) is then compared against a best possible virtual team for that particular team. These comparison teams, or peers, form a frontier against which a particular team is measured. Let us assume that the goal is to minimize the inputs used to produce a certain level of output. This is a plausible goal since we could find other tasks for skilled programmers.

Determining this best possible virtual team for each team is not difficult in two dimensions but it becomes very difficult in higher order situations. This problem is much better analyzed as a linear optimization problem. The matrices $X$ and $Y$ refer to the sets of inputs and outputs respectively. The vector $\lambda$ describes the construction of the virtual team used in comparison with the particular team under consideration. The vectors $X_{0}$ and $Y_{0}$ are the inputs and outputs of the particular team (or DMU) being analyzed. The value, $\theta$, is the proportion by which the input of the virtual team can be reduced and still produce at least as much of each output at the team being studied. Therefore, $\theta$ indicates the input-oriented radial relative efficiency of the team.

$$
\begin{array}{ll}
\min _{\theta, \lambda} \theta, & \\
\text { s.t. } & Y \lambda \geq Y_{0}, \\
& X \lambda \leq \theta X_{0}, \\
& \lambda, \geq 0 .
\end{array}
$$

An efficiency score of $\theta=1$ for a particular team indicates that there is no possible DMU (real or virtual) that can produce at least as much of each output using no more of any input than this team. We would then deem this team to be radially efficient. Our results are in Table II.

TABLE II

Simple RAdial CCR INPUT-ORIENTEd PRIMAL RESUlts

\begin{tabular}{|c|c|c|c|c|c|c|}
\hline Team & $\lambda_{1}$ & $\lambda_{2}$ & $\lambda_{3}$ & $\lambda_{4}$ & $\lambda_{5}$ & Efficiency \\
\hline $\mathbf{1}$ & & 0.962 & & 0.1 & & 0.801 \\
\hline $\mathbf{2}$ & & 1 & & & & 1.000 \\
\hline $\mathbf{3}$ & & & 1 & & & 1.000 \\
\hline $\mathbf{4}$ & & & & 1 & & 1.000 \\
\hline $\mathbf{5}$ & & 0.462 & & 0.923 & & 0.923 \\
\hline
\end{tabular}

Not all teams that are radially efficient are really making the best use of their inputs to make outputs though. For example compare Team 3, which was radially efficient, to a doubled Team 4. Both Team 3 and the doubled Team 4 had the same number of programmers and completed the same number of projects but Team 3 finished less lines of code. This indicates slack in that output for Team 3. We should then expand our definition of efficiency to include only those teams (or DMUs) that are radially efficient and do not use any slack inputs or outputs. After determining the maximum radial contraction possible (minimum $\theta$ ), we should try to maximize the slacks of the inputs and the outputs.

Notationally, we can combine these two steps into a single linear programming formulation using an infinitesimal, $\varepsilon$, that is greater than zero but smaller than any real positive number. This enables the minimization of the radial efficiency score to take precedence over the maximization of the slacks.

$$
\begin{array}{ll}
\min _{\theta, \lambda, \mathrm{s}^{+}, \mathrm{s}^{-}} & \theta-\varepsilon \mathrm{s}^{+}-\varepsilon \mathrm{s}^{-}, \\
\text {s.t. } & Y \lambda-Y_{0}-\mathrm{s}^{+}=0, \\
& \theta X_{0}-X \lambda-\mathrm{s}^{-}=0, \\
& \lambda, \mathrm{s}^{+}, \mathrm{s}^{-} \geq 0 .
\end{array}
$$

Attempting to approximate $\varepsilon$ by a small number, however, may lead to subtle computational problems as documented in [1]. Therefore, it is often solved as a two-phase procedure. The two-phase procedure is really just a simple example of 
preemptive goal programming. The objective of the first phase (linear program) is to minimize $\theta$. The second phase's objective is to minimize the negative sum of slacks (or maximize the sum of slacks) given that $\theta$ must be unchanged from the result found in the first phase. Although Team 3 is radially efficient, it was only weakly efficient and is outperformed by Team 4 . This would result in a higher target of performance for Team 3 based upon Team 4's performance.

\section{ADDITIONAL STANDARD MODELS}

\section{A. CCR Dual Formulation}

Traditionally, each software development team might be rated by some ratio of aggregated outputs over aggregated inputs. As discussed earlier, financial values often provide a useful method for aggregation. The programmers' salaries could be used in this case to aggregate the inputs. Assume that the average annual salary for a senior programmer is $\$ 70,000$ and for junior programmer, $\$ 40,000$. The outputs might be harder to aggregate since it may be hard to relate lines of code to a dollar figure. Let us assume each project brings in revenue of $\$ 100,000$ and a line of code is valued at an additional $\$ 100$. We could now easily calculate aggregate inputs and outputs. From these aggregate values, we could then calculate a yield and relative rating of each team on the basis of the yield. This type of procedure would be a fixed-weight measure.

\begin{tabular}{c|c|c|c|c}
\multicolumn{2}{c}{ Table III } \\
FiXed Weight Evaluation \\
Team & $\begin{array}{c}\text { Salary } \\
\text { Cost } \mathbf{( \$ K )}\end{array}$ & $\begin{array}{c}\text { Deliverable } \\
\text { Value (\$K) }\end{array}$ & Yield & Rating \\
\hline $\mathbf{1}$ & 840 & 1650 & 1.96 & 0.69 \\
$\mathbf{2}$ & 630 & 1800 & 2.86 & 1.00 \\
$\mathbf{3}$ & 1050 & 2250 & 2.14 & 0.75 \\
$\mathbf{4}$ & 525 & 1200 & 2.29 & 0.80 \\
$\mathbf{5}$ & 840 & 1925 & 2.29 & 0.80
\end{tabular}

If we have accurate prices or weights for each input and output, this can be a very easy and valuable technique. (See [26] for a nice and succinct overview of some fixed-weight techniques productivity analysis techniques.) In this example, it appears to be straightforward to aggregate both the inputs and the outputs through a common set of units such as dollars. The example could be easily modified to make it much more difficult to aggregate. For example, quality measures could be included as an output, development tools could be included as an input, and salaries could include international programmers with different salary units of pay. In these cases, the tradeoffs between inputs or the tradeoffs between outputs are much more difficult to make.

The dual formulation of DEA can be thought of as being analogous to the increasingly popular method of annual review known as "self-evaluation." We will allow each team the opportunity to rate themselves by selecting the "prices" for each input, $v$, and the "prices" for each output, $\mu$, that cast themselves in the best possible light. The one restriction is that no team can pick a pricing (or weighting) scheme that would give any other team a score greater than one. Clearly a team that does a lot of short projects might then want to put a higher weight on the number of projects than on the lines of code. Similarly, a team of junior programmers might put a far higher weight on senior programmers than on junior programmers to make themselves look better.

$$
\begin{aligned}
\max _{v, \mu} & \frac{\mu \cdot Y_{0}}{v \cdot X_{0}} \\
\text { s.t. } & \frac{\mu \cdot Y_{j}}{v \cdot X_{j}} \leq 1, \quad \text { foreachDMU } j \in[1, \ldots, n] \\
& \mu, v \geq 0 .
\end{aligned}
$$

Although this problem is a nonlinear function, as originally demonstrated in [13] it can be easily linearized by multiplying out the denominator of each constraint and by setting the denominator of the objective function to be equal to one. Lastly, we would like to eliminate the possibility of anyone achieving a determination of being efficient by disregarding one of the inputs or outputs entirely. This situation can be resolved by including a constraint that each input and output weight must be greater than or equal to an infinitesimal. The resulting linear program is given in (4).

$$
\begin{array}{ll}
\max _{v, \mu} & \mu \cdot Y_{0}, \\
\text { s.t. } & v \cdot X_{0}=1, \\
& \mu \cdot Y_{j} \leq v \cdot X_{j}, \quad \text { foreachDMU } j \in[1, \ldots, n] \\
& \mu, v \geq \varepsilon .
\end{array}
$$

\section{B. BCC Primal Formulation}

When looking at the results in Table II, we see the effects of another major assumption of the DEA model as written. Team 3 is compared to the doubled Team 4 . This assumes that Team 4 will operate just as efficiently at twice its current size. In essence, the model assumes that doubling the programmers on a project will double the code produced. This assumption is termed constant returns to scale. However, this is a major and often unrealistic assumption. In the application of software development, it has been stated [11] that adding programmers seldom yields an equivalent increase in output thereby displaying decreasing returns to scale. For more detailed discussions of the economies of scale for software programming, see $[4,5,7]$.

The assumption of constant returns to scale in the primal formulation is a result of the freedom of the $\lambda$ 's in constructing targets of performance. Banker, Charnes, and Cooper, [6] demonstrated a simple way to unrestrict the returns to scale assumption was to restrict the values of the $\lambda$ 's. As in the case of the CCR model, this model is widely referred to by the 
author's initials of BCC. In essence, it is based on restricting how virtual teams are created. By adding the restriction that the $\lambda$ 's must sum to one, all virtual teams must lie on a plane between actual teams. This restriction of convexity creates a much tighter frontier surrounding the data and a more varied surface. This surface can now display different returns to scale at different locations. The new formulation is shown below:

$$
\begin{array}{ll}
\min _{\theta, \lambda, \mathrm{s}^{+}, \mathrm{s}^{-}} & \theta-\varepsilon \mathrm{s}^{+}-\varepsilon \mathrm{s}^{-}, \\
\text {s.t. } \quad & Y \lambda-Y_{0}-\mathrm{s}^{+}=0, \\
& \theta X_{0}-X \lambda-\mathrm{s}^{-}=0, \\
& \sum_{j=1}^{n} \lambda_{j}=1, \\
& \lambda, \mathrm{s}^{+}, \mathrm{s}^{-} \geq 0 .
\end{array}
$$

By looking at Table IV, we can see how this affects our problem. Team 3 is still considered efficient but now lies on the frontier rather than being compared to a doubled Team 4. Teams 1 and 5 are still inefficient but have slightly higher efficiency scores than with the previous analysis. This occurs because the frontiers to which they are compared have been restricted into tighter areas. However, the main change lies in the teams used as comparisons.

TABLE IV

BCC INPUT-ORIENTED PRIMAL EVALUATION

\begin{tabular}{|c|c|c|c|c|c|c|}
\hline Team & $\lambda_{1}$ & $\lambda_{2}$ & $\lambda_{3}$ & $\lambda_{4}$ & $\lambda_{5}$ & Efficiency \\
\hline $\mathbf{1}$ & & 0.9 & & 0.1 & & 0.808 \\
\hline $\mathbf{2}$ & & 1 & & & & 1.000 \\
\hline $\mathbf{3}$ & & & 1 & & & 1.000 \\
\hline $\mathbf{4}$ & & & & 1 & & 1.000 \\
\hline $\mathbf{5}$ & & 0.593 & 0.352 & 0.056 & & 0.937 \\
\hline
\end{tabular}

\section{IMPORTANT MODELING VARIATIONS AND EXTENSIONS}

\section{A. Overview}

Since the development of DEA, several variations have been proposed which assist in refining the accuracy of the model. These variations and extensions take several forms. We will address methods of weight restrictions and nontraditional types of inputs and outputs. Work is being conducted to develop and improve statistical interpretations to DEA results.

\section{B. Weight Restrictions}

An important extension allows the analyst to limit the range in which the weights or "prices" can vary in the dual formulation. The dual formulation allows each DMU to choose the set of weights which gave it the highest score. However, the analyst may possess knowledge to the contrary. For example, we may not allow the junior programming team mentioned in section D to place all the weight on the senior programmers because we know from experience that junior programmers have the high cost of training and turnover. So we may restrict the junior programming weight to be over a minimum proportion of the senior programmers' cost.

So, the restriction of these weights allows the expert opinion of the analyst to be included in the model. It is important to recognize that not using a model that allows for weight restrictions implicitly assumes that there is no limit to the relative weights of the inputs or of the outputs.

Weight restriction techniques have another major advantage. Limiting the freedom of a unit to select unrealistic weights assists the analyst in performing realistic evaluations with a limited number of DMUs. A general rule of thumb is one should have a set of DMUs equal to three times the sum of the number of inputs and outputs in a model. For a further discussion of this which considers the motives behind the model see [2]. This paper, however, does not consider the impact of weight restrictions.

A method of restricting weights in DEA that does not require a priori knowledge of weights for a particular application is cross-efficiency. The use and implications of cross-efficiency are subtle and are discussed in more detail in other PICMET papers.

\section{Types of Inputs and Outputs}

DEA assumes that the inputs and outputs have a variety of properties including being quantifiable and controlled by the DMU. It has been found that in certain applications one or more of the inputs or outputs does not satisfy these properties.

Difficult to quantify inputs and outputs have been typically addressed by the use of models that allow for categorical variables. Categorical variables are those having a type such as "small, medium or large" rather than a quantifiable valuable. The issue of categorical inputs and outputs has been examined by a number of researchers $[9,17,23,27,38]$. The basic technique is to restrict the comparison set. An example using an ordinal categorical variable could be found in the application of software programmers. Consider using the categorical input variable of location with two values: "onsite" and "off-site". Since the on-site programmers presumably have access to far better equipment and more resources, we might not want to include them in the comparison group for the "off-site" teams. Therefore, all "offsite" teams would only be compared to each other. However, the "on-site" teams would be compared to the entire set of programming teams.

To illustrate the issue of discretionary versus nondiscretionary inputs and outputs, we consider again our software programmers. Suppose this model was used to measure the effectiveness of the senior programmers at managing the programming process. If so, they might not have any control over the number of senior programmers on their team; this having been decided at higher levels. The senior programmers would only be able to control the number of 
junior programmers assigned to the team. Therefore, a model judging their performance should distinguish between the inputs under their control (the discretionary inputs) and the inputs beyond their jurisdiction (the nondiscretionary inputs). A variety of authors [8, 14, 22, 37] have motivated and developed models that account for nondiscretionary or partially discretionary inputs and/or outputs.

\section{CAlculating DEA}

\section{A. Computational Difficulties}

The linear programming formulations for DEA may at first glance appear to be rather simple. In fact it is simple enough that it is now often included in introductory management science textbooks. This may lead people to rely on develop their own software for performing DEA. Unfortunately, the simplicity of the formulations belie more subtle computational issues. DEA problems actually have a number of relatively uncommon characteristics that may cause difficulty. These problems tend to have highly degenerate solutions. For example, in the primal formulation it is not unusual to have a solution where there are far fewer nonzero $\lambda$ values than there are input and output constraints. Also, although DEA problems tend to be much smaller than large scale optimization problems, data matrices are nearly $100 \%$ dense as opposed to the sparse matrices that commercial linear programming software is traditionally tailored to address. Lastly, as discussed earlier, it is important to incorporate a two-phase approach rather than attempting to approximate a nonArchimedean infinitesimal.

\section{B. Software Systems}

Since the use of DEA has not been as widespread in the statistics community, there has not been a great demand to include it in standard research support packages. Instead, a variety of systems exist which specifically perform DEA. A couple of systems with graphical user interfaces such as Warwick-DEA and Frontier Analyst have recently been developed that incorporate a variety of common models and extensions. Another option that allows the user to more easily extend models is to use a template in a general purpose algebraic modeling languages. Basic templates have been developed in GAMS [34] and AMPL. Lastly, special purpose, batch oriented programs have also been developed that take special advantage of structures in the DEA problems.

\section{TECHNOLOGY MANAGEMENT APPLICATIONS}

Initially DEA was developed for use in the evaluation of nonprofit institutions where it was difficult or meaningless to attempt to aggregate inputs and outputs into a simple bottomline profit/loss situation. Analysts, however, have found it to be a useful technique in a wide range of areas. DEA was used to evaluate the performance of company subunits, such as warehousing operations [21, 25, 39]. As has already been discussed, software development has been examined [4, 5, 7] and continues to receive attention as this sector of the economy has grown in importance and complexity. The changing paradigms of manufacturing have also resulted in a need for powerful analytical tools including DEA [12, 24, 36, 41, 42, 49]. Recently, DEA has been brought to bear on the subject of technology selection and evaluation [3, 28]. As previously moribund industries deregulate, efficiency analyses will assist them to determine ways to operate better $[10,23,30,31,40$, $44,45,48,50]$. Product life cycle and marketing has also seen recent contributions made using DEA $[32,46]$ as well as R\&D project selections [35].

\section{CONCLUSIONS}

Data envelopment analysis has been a useful tool that is starting to see application in areas of the management of engineering and technology. It will continue to grow in importance as analysts apply DEA in a variety of settings that require refinements.

\section{REFERENCES}

[1] A. I. Ali, "Data envelopment analysis: computational issues," Computers, Environment and Urban Systems, vol. 14, pp. 157-65, 1990.

[2] T. R. Anderson, K. B. Hollingsworth, and M. L. Durchholz, "Estimates of the Number of DMUs Needed for DEA as a Function of Model Size," Working Paper, pp. 1-17, 1996.

[3] R. C. Baker and S. Talluri, "A closer look at the use of data envelopment analysis for technology selection," Computers \& Industrial Engineering, vol. 32, pp. 101-108, 1997.

[4] R. Banker and C. Kemerer, "Factors affecting software maintenance productivity: an exploratory study," presented at Proceedings of the 8th International Conference on Information Systems, Pittsburgh, PA, 1987.

[5] R. D. Banker, H. Chang, and C. F. Kemerer, "Evidence on economies of scale in software development," Information \& Software Technology, vol. 36, pp. 275-282, 1994.

[6] R. D. Banker, A. Charnes, and W. W. Cooper, "Some models for estimating technical and scale inefficiencies in data envelopment analysis," Management Science, vol. 30, pp. 1078-1092, 1984.

[7]R. D. Banker and C. F. Kemerer, "Scale economies in new software development," IEEE Transactions on Software Engineering, vol. 15, pp. 1199-205, 1989.

[8] R. D. Banker and R. C. Morey, "Efficiency analysis for exogeneously fixed inputs and outputs," Operations Research, vol. 34, pp. 513-21, 1986.

[9] R. D. Banker and R. C. Morey, "The use of categorical variables in data envelopment analysis," Management Science, vol. 32, pp. 1613-27, 1986.

[10] W. F. Bowlin, "A characterization of the financial condition of the United States' aerospace-defense industrial base," Omega, vol. 23, pp. 539-55, 1995.

[11] F. P. J. Brooks, The Mythical Man-Month - Essays on Software Engineering. Reading: Addison-Wesley, 1982.

[12] Y.-L. Chang, T. Sueyoshi, and R. S. Sullivan, "Ranking dispatching rules by data envelopment analysis in a job shop environment," IIE Transactions, vol. 28, pp. 631-642, 1996.

[13] A. Charnes and W. W. Cooper, "Programming with linear fractional functionals," Naval Research Logistics Quarterly, vol. 9, pp. 181-185, 1962.

[14] A. Charnes, W. W. Cooper, B. Golany, and L. Seiford, "Foundations of data envelopment analysis for Pareto-Koopmans efficient empirical production functions," Journal of Econometrics, vol. 30, pp. 91-107, 1985. 
[15] A. Charnes, W. W. Cooper, A. Y. Lewin, and L. M. Seiford, "Data Envelopment Analysis: Theory, Methodology and Applications," . Boston: Kluwer, 1994.

[16] A. Charnes, W. W. Cooper, and E. Rhodes, "Measuring the efficiency of decision making units," European Journal of Operations Research, vol. 2, pp. 429-44, 1978.

[17] A. Charnes, J. J. Rousseau, and J. H. Semple, "Nonarchimedean infinitesimals, transcendentals and categorical inputs in linear programming and data envelopment analysis," International Journal of Systems Science, vol. 23, pp. 2401-6, 1992.

[18] G. Debreu, "The coefficient of resource utilization," Econometrica, vol. 19, pp. 273-292, 1951

[19] P. F. Drucker, "The new productivity challenge," Harvard Business Review, vol. 69, pp. 69-79, 1991.

[20] M. J. Farrell, "The measurement of productive efficiency," Journal of the Royal Statistical Society, vol. 120, pp. 253-281, 1957.

[21] E. H. Frazelle and S. T. Hackman, "The warehouse performance index: a single-point metric for benchmarking warehouse performance," Material Handling Research Center MHRC-TR-93-14, 9/20/94 1994.

[22] B. Golany and Y. Roll, "Some extensions of techniques to handle nondiscretionary factors in data envelopment analysis," Journal of Productivity Analysis, vol. 4, pp. 419-432, 1993.

[23] B. Golany, Y. Roll, and D. Ryback, "Measuring efficiency of power plants in Israel by data envelopment analysis," IEEE Transactions on Engineering Management, vol. 41, pp. 291-301, 1994.

[24] K. T. Heimerman, "Efficient Set Relations Among Data Envelopment Analysis Models and Resource Use Efficiency In Manufacturing," : University Of Massachusetts, 1993, pp. 362.

[25] K. B. Hollingsworth, "A Warehouse Benchmarking Model Utilizing Frontier Production Functions," in Industrial and Systems Engineering. Atlanta: Georgia Institute of Technology, 1995.

[26] J. Jurison, "Defining and Measuring Productivity," in Productivity in the Office and Factory, Decision Making and Operations Management Series, P. Gray and J. Jurison, Eds. Danvers: Boyd and Fraser, 1995, pp. 11-21.

[27] W. A. Kamakura, "A note on 'the use of categorical variables in data envelopment analysis'," Management Science, vol. 34, pp. 1273-6, 1988.

[28] M. Khouja, "The use of data envelopment analysis for technology selection," Computers \& Industrial Engineering, vol. 28, pp. 123-32, 1995.

[29] T. C. Koopmans, "An analysis of production as an efficient combination of activites," in Activity Analysis of Production and Allocation, vol. 13, Cowles Commission for Research in Economics, T. C. Koopmans, Ed. New York: John Wiley and Sons, Inc., 1951.

[30] S. K. Majumdar, "X-efficiency in emerging competitive markets: The case of U.S. telecommunications," Journal of Economic Behavior \& Organization, vol. 26, pp. 129-144, 1995.

[31] S. K. Majumdar and H.-h. Chang, "Scale efficiencies in US telecommunications: An empirical investigation," Managerial \& Decision Economics, vol. 17, pp. 303-318, 1996.

[32] P. S. Murthi, K. Srinivasan, and G. Kalyanaram, "Controlling for observed and unobserved managerial skills in determining first-mover market share advantages," Journal of Marketing Research, vol. 33, pp. 329-336, 1996.
[33] O. B. Olesen and N. C. Petersen, "Indicators of ill-conditioned data sets and model misspecification in data envelopment analysis: An extended facet approach," Management Science, vol. 42, pp. 205-219, 1996.

[34] O. B. Olesen and N. C. Petersen, "A presentation of GAMS for DEA," Computers \& Operations Research, vol. 23, pp. 323-339, 1996.

[35] M. Oral, O. Kettani, and P. Lang, "A methodology for collective evaluation and selection of industrial R\&D projects," Management Science, vol. 37, pp. 871-885, 1991.

[36] C. Parkan, "Calculation of operational performance ratings," International Journal of Production Economics, vol. 24, pp. 165-1 73, 1991.

[37] S. C. Ray, "Data envelopment analysis, nondiscretionary inputs and efficiency: an alternative interpretation," Socio-Economic Planning Sciences, vol. 22, pp. 167-176, 1988.

[38] J. J. Rousseau and J. H. Semple, "Notes: Categorical outputs in data envelopment analysis," Management Science, vol. 39, pp. 384-386, 1993.

[39] M. Schefczyk, "Industrial benchmarking: a case study of performance analysis techniques," International Journal of Production Economics, vol. 32, pp. 1, 2-11, 1993.

[40] M. Schefczyk, "Operational performance of airlines: an extension of traditional measurement paradigms," Strategic Management Journal, vol. 14, pp. 301-317, 1993.

[41] S. M. Shafer and J. W. Bradford, "Efficiency measurement of alternative machine component grouping solutions via data envelopment analysis," IEEE Transactions on Engineering Management, vol. 42, pp. 159-165, 1995.

[42] J. Shang and T. Sueyoshi, "A unified framework for the selection of a flexible manufacturing system," European Journal of Operational Research, vol. 85, pp. 297-315, 1995.

[43] P. Smith, "Misspecification bias in data envelopment analysis," University of York, Discussion Papers 15, May 19931993.

[44] T. Sueyoshi, "Divestiture of Nippon Telegraph and Telephone," Management Science, vol. 42, pp. 1326-1351, 1996.

[45] D. T. Taylor and R. G. Thompson, "The efficient utility: Labor, capital, \& profit," Public Utilities Fortnightly, vol. 133, pp. 25-29, 1995.

[46] S. Thore, F. Phillips, T. W. Ruefli, and P. Yue, "DEA and the management of the product cycle: The U.S. computer industry," Computers \& Operations Research, vol. 23, pp. 341-356, 1996.

[47] H. Tulkens, "On FDH efficiency analysis: some methodological issues and applications to retail banking, courts, and urban transit," Journal of Productivity Analysis, vol. 4, pp. 183-210, 1993.

[48] L. C. Walters, G. C. Cornia, D. W. Shank, C. Gerschefske, and et al., "Measuring obsolescence in regulated firms: Enhancements to the cost approach,” Assessment Journal, vol. 1, pp. 47-58, 1994.

[49] C. H. Wang, "The Impact Of Manufacturing Performance On Firm Performance, the Determinants Of Manufacturing Performance, and the Shift Of the Manufacturing Efficiency Frontier," : State University Of New York At Buffalo, 1993, pp. 233.

[50] S. Yaisawarng and J. D. Klein, "The effects of sulfur dioxide controls on productivity change in the U.S. electric power industry," Review of Economics \& Statistics, vol. 76, pp. 447-460, 1994. 